\title{
Inhibition of Corrosion of Aluminum Alloy AA8011 in Alkaline Medium Using Palisota hirsute Extract
}

\author{
NNANNA Lebe A. ${ }^{1, a^{*}}$, UCHENDU Kings $0^{2, b}$, IKWUAGWU Glory ${ }^{3, c}$, \\ JOHN Wisdom O. ${ }^{2, \mathrm{~d}}$, IHEKORONYE Uche $\mathrm{e}^{4, \mathrm{e}}$
}

\author{
${ }^{1}$ Physics Department, Michael Okpara Uni. of Agric. Umudike. PMB 7267, Umuahia. Nigeria \\ ${ }^{2}$ Physics/Electronics Department, Abia State Polytechnic, P. M. B. 7166, Aba, Abia State \\ ${ }^{3}$ Department of Environmental Chemistry, Enugu State University of Sci. \& Tech., Enugu \\ ${ }^{4}$ Civil Engineering Department, Abia State Polytechnic, P. M. B. 7166, Aba, Abia State \\ alebennanna@yahoo.com*, bkingsuchendu@gmail.com, 'cglowingglo7@gmail.com, \\ djwisdomoji@yahoo.com, ${ }^{\mathrm{e} u c h e n d u i h e k o r o n y e @ y a h o o . c o m ~}$
}

Keywords: 0.25M KOH, AA8011, adsorption, Palisota hirsute, Langmuir, adsorption isotherm.

\begin{abstract}
Gravimetric technique was used to study the inhibition of aluminium alloy AA8011 in an alkaline medium using an eco-friendly inhibitor, Palisota hirsute. The study revealed that the extract reduced the corrosion rate of aluminium AA8011 from $0.407 \mathrm{~mm} / \mathrm{yr}$ to as low as $0.106 \mathrm{~mm} / \mathrm{yr}$ in $0.25 \mathrm{M} \mathrm{KOH}$ after being exposed for five hours. The inhibition efficiency was found to increase as the concentration of the plant extract in the medium increased. The adsorption studies, computed from the experimental data revealed Langmuir isotherm as the best model for the isotherm $\left(r^{2}=0.999\right)$ on the mild steel surface. Gibb's free energy of adsorption was also calculated and gotten to be $15.61 \mathrm{kJmol}^{-1}$, suggesting that inhibitor molecules have been spontaneously adsorbed onto the aluminum surface through physical adsorption mechanism.
\end{abstract}

\section{INTRODUCTION}

Aluminum and its alloy are the second largest used material next to iron and its alloys due to their lightweight, strength, durability, formability and corrosion resurface. Prevention of corrosion of aluminum has been a subject of numerous studies due to their high technological value and wide range of industrial and house hold application [1 - 3]. The corrosion resistance of aluminum and its alloy is attributable to the formation of stable protective thin film of aluminum oxide when first produced and exposed to the atmosphere. Nevertheless, when exposed to an aggressive environment (acidic or alkaline), they are prone to corrosion and degradation. The protective oxide film is of atmospheric character and easily dissolved in acidic and alkaline media $[4,5]$ leading to a sequence electrochemical reaction. Corrosion is accompanied by many conjugated cathodic process in which hydrogen gas evolution is often predominant in strong acid and alkaline solution [6 - 8]. Corrosion control of aluminum and its alloys can be enhanced by addition of some inorganic substances to the corrodent. The substance include phosphate, chromate, dichromates, silicates, bromated, arsenates, tungstates, molybdates, chloride and their likes [9 - 12]. These inorganic inhibitors exhibit toxic effects and are therefore not environmentally friendly. As a result, there has been a search for corrosion inhibitors which are not harmful to the environment while they protect the metal against corrosion.

It has been found that certain organic substances containing polar function with nitrogen, sulphur and/or oxygen atoms in the conjugated system exhibit good inhibiting properties of steels in acidic and alkaline environment [13 - 15]. Plant products are organic in nature and some of the constituents including tannins, alkaloids, saponins, essential oils, flavones organic and amino acids are known to exhibit inhibiting action [16 - 20]. In addition to these organic materials, they also contain proton functions and conjugated double bond and aromatic rings, which are the major adsorption centers. In view of our interest in creating a green-environment [21 - 27], where hazard are at minimal level- not even evolving from what we use in protection, this study uses a naturally 
occurring green leaf, Palisota hirsute, a highly medicinal leaf to inhibit the corrosion of aluminum in alkaline medium, furthermore the study goes further to study the Temkin and Langmuir adsorption isotherm.

\section{METHODOLOGY}

Aluminium sheets of type AA8011 having weight percentage composition of $\mathrm{Si}-0.240 \%$, $\mathrm{Fe}-0.241 \%$, Cu- $0.035 \%$, Mn- $0.102 \%$, Ti- $0.019 \%$, Pb-0.014\%, Zn- $0.043 \%$ the remainder being Al were used in this study. The test coupons were prepared having a dimension of $20 \times 20 \mathrm{~mm}$ and thickness $1.11 \mathrm{~mm}$, were polished mechanically with Si-emery papers of grade nos 220, 400 and 600 degreased with ethanol and acetone having been washed with distilled water. The coupons were air-dried appropriately before any measurement was taken on it using the JA 1003A electronic weighing machine, of accuracy \pm 0.005 .

Palisota hirsute used for this research was obtained from Osusu in Isialangwa North Local government of Abia State, air dried and pulverized. $10 \mathrm{~g}$ of the ground leaf was digested in $0.24 \mathrm{~L}$ of $0.25 \mathrm{M} \mathrm{KOH}$, refluxed, filtered and stored. From the stock solution, the filtrate was used to prepare a concentration range of $0.1 \mathrm{~g} / \mathrm{L}$ to $0.5 \mathrm{~g} / \mathrm{L}$.

The dried and measured coupons were introduced into the respective test solutions, using the different concentrations as prepared. At the end of the tests, the specimens were carefully washed in absolute ethanol having used Nitric acid to quench further corrosions from taking place and then reweighed.

The experiment was repeated in triplicates and the mean value was reported. All materials used were of analytical grade. Doubly distilled water was used in all preparations. The temperature was controlled within $\pm 0.2^{\circ} \mathrm{C}$.

\section{METHODOLOGY}

\section{CORROSION RATES AND GRAVIMETRIC MEASUREMENTS}

The gravimetric method of studying corrosion is the most popularly used method of determining corrosion rates of metals in corrosive media. This method was used to study the weight loss of Aluminum in $0.25 \mathrm{M} \mathrm{KOH}$ after five (5) hours of exposure. The corrosion rate was determined from the equation below:

$C R=\frac{K \Delta w}{\rho A t}$

$\Delta w=w_{i}-w_{f}$

Where $C R$ - Corrosion rate in $\mathrm{mm} / \mathrm{yr} ; K$ - Corrosion rate constant (534 mpy; mils per year); $\Delta w$ - Weight loss in grams; $\rho$ - Density of the steel $\left(\mathrm{g} / \mathrm{cm}^{3}\right) ; A$ - The exposed area of the coupon $\left(\mathrm{cm}^{2}\right) ; t$ - Immersion time (hrs); $w_{i}$ - Initial weight of the metal in grams and $w_{f}$ - weight of the metal after exposure in the corrosive media

\section{INHIBITION EFFICIENCY}

The inhibition efficiency of the Palisota hirsute leaf extracts on the corrosion of the aluminium in $0.25 \mathrm{M} \mathrm{KOH}$ containing different concentrations of the leaf extract was computed by using the relation $[4,5,10]$ :

$I \%=\left(1-\frac{\rho_{\text {inh }}}{\rho_{\text {blank }}}\right) \times 100$

Where I\% represents the inhibition efficiency expressed in percentage; $\rho_{\text {inh }}$ is the corrosion rate in the presence of the inhibitor while $\rho_{\text {blank }}$ is the corrosion rate in the absence of inhibitor. 


\section{RESULTS AND DISCUSSIONS}

\section{Gravimetric Technique and Corrosion Rates}

The corrosion rates of the aluminium in $0.25 \mathrm{M} \mathrm{KOH}$ in the absence and presence of Palisota hirsute leaf extract were determined at room temperature $(303 \mathrm{~K})$. Figure 1 below shows a graphical representation of the variation of corrosion rate with concentration of Palisota hirsute leaf extract. The corrosion rate was studied for five hours of exposure of the aluminium alloy in $0.25 \mathrm{M} \mathrm{KOH}$. It can be seen from figure 1 that corrosion rate decreases with an increase in the concentration of the inhibitor.

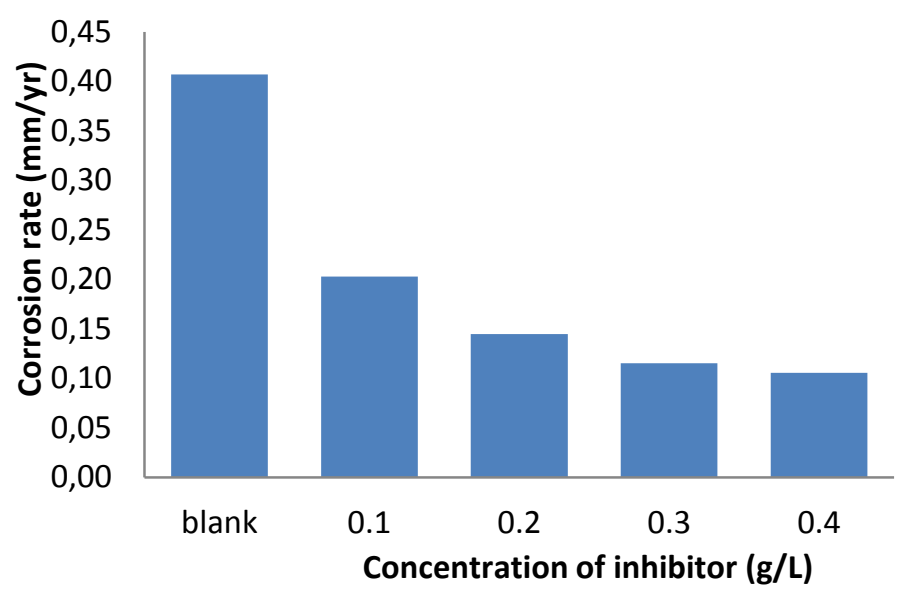

Figure 1: Variation of corrosion rate of aluminium 8011 in $0.25 \mathrm{M} \mathrm{KOH}$ with different concentrations of Palisota hirsute extract.

Subsequently, a plot of the weight loss of the metal due to corrosion was plotted (Figure 2). It showed that there was a reduction in the weight loss of the metals exposed to the corrosive environment as a result of the reduction in the corrosion rates which reduced as the concentration of the inhibitor increased.

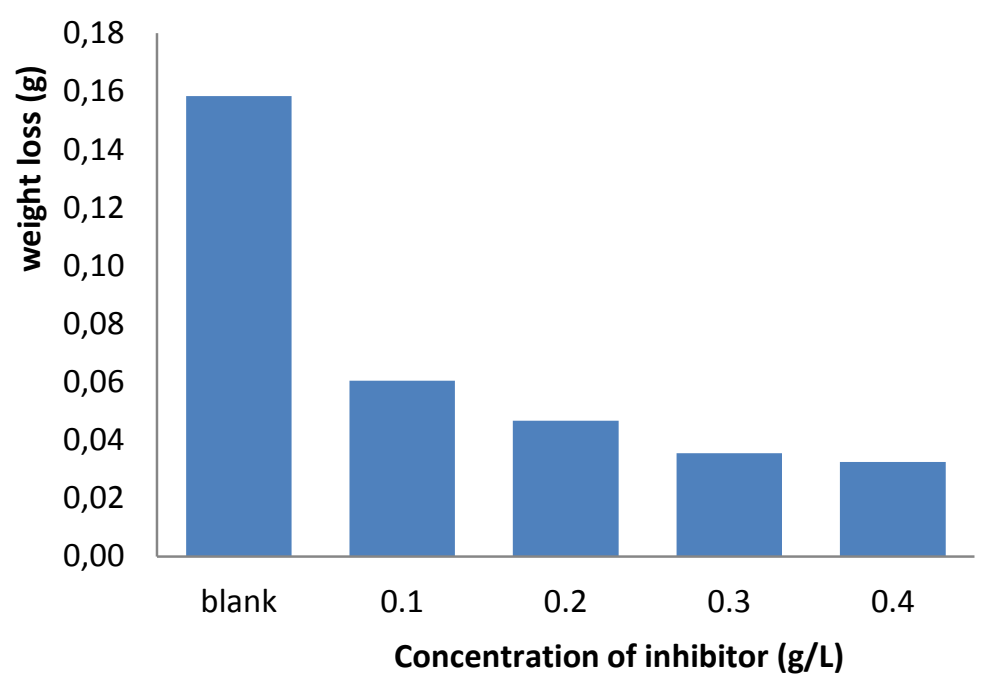

Figure 2: Variation of weight loss (in grams) of aluminium 8011 in $0.25 \mathrm{M} \mathrm{KOH}$ with different concentrations of Palisota hirsute extract.

\section{Inhibition efficiency}

A graph of the inhibition efficiency, as calculated using equation (3) was plotted in Figure 3. It showed an increase in inhibition efficiency as the concentration of the inhibitor increased. The rate of increase was higher in lower concentrations and as the concentration got higher, the inhibition efficiency increased at a low rate. This indicates that the effectiveness of Palisota hirsute 
in the retarding/inhibition of corrosion do not improve indefinitely with increase in inhibitor concentration. A point is reached at which an increase in the inhibitor concentration produces only a very small increase in inhibition efficiency. A similar conclusion has been reached by $[12,15]$ who studied the inhibitive effect of Solanum melongena L. Leaf extract on the corrosion of aluminium in tetraoxosulphate (VI) acid and Corrosion Inhibition effect of Anthocleista djalonensis on Mild Steel in $1.0 \mathrm{M} \mathrm{HCl}$ respectively. An optimum of $74.1 \%$ inhibition efficiency was obtained at $0.4 \mathrm{~g} / \mathrm{L}$ concentration of Palisota hirsute.

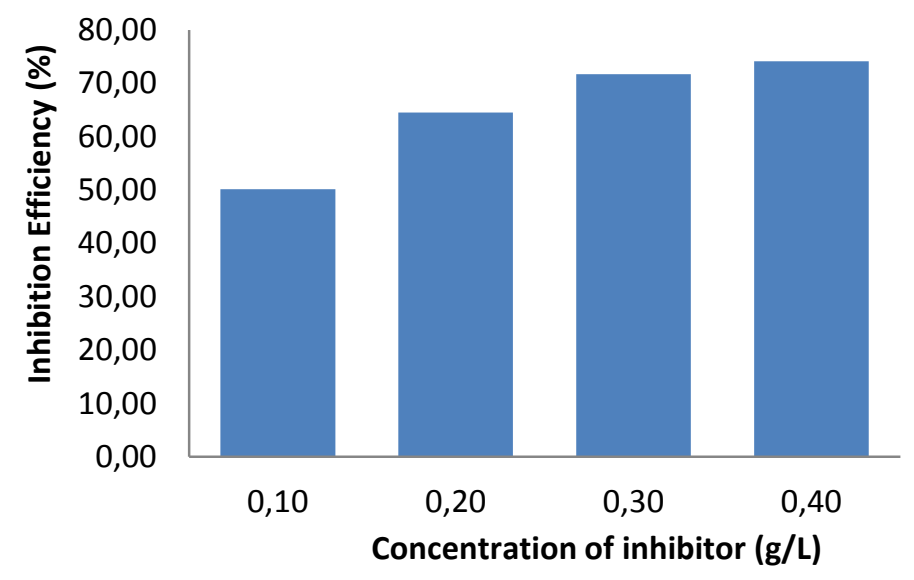

Figure 3: Variation of inhibition efficiency with concentration of Palisota hirsute leaf extract for aluminium in $0.25 \mathrm{M} \mathrm{KOH}$.

The increase in inhibition efficiency with increase in concentration of Palisota hirsute leaf extract suggests, as also explained by Lebe et al., [21] that some of the molecules of the inhibitor are adsorbed on the metal surface thereby protecting the "covered" surface from further corrodent attack. Increasing the inhibitor concentration increases the degree of surface coverage, $\theta$ of the metal surface. The adsorbed molecules on the metal surface constitute a barrier to charge and mass transfer between the metal and the corrodent, thereby protecting the metal surface from corrodent attack. The larger the degree of surface coverage resulting from enhanced adsorption of molecules of the plant extract, the greater the protection to corrosion offered by the inhibitor [21, 23].

\section{Mechanism of adsorption and Adsorption Isotherms}

Inemesit and Nnanake-Abasi, [28] reported that one of the mechanisms by which inhibitors retard corrosion is by the physical adsorption of the molecules on the metal surface. In such situations, investigating the possible adsorption mode is done by testing the obtained experimental data with several adsorption isotherms. This exercise will clarify ones understanding of the corrosion inhibition mechanism. Generally, the expression for several adsorption isotherms is [13, 21]:

$f(\theta, x) \exp (-\alpha \theta)=k C$

where $\mathrm{f}(\theta, \mathrm{x})$ is the configuration factor whose functional form depends on the physical model adopted and assumptions made in deriving the isotherm, $\theta$ is the degree of surface coverage, $x$ is known as the size ratio which gives the number of water molecule replaced by the inhibitor molecule, $\alpha$ is a molecular interaction parameter whose value depends on the type of molecular interactions in the adsorption layer and the degree of homogeneity of the surface, $\mathrm{C}$ is the inhibitor concentration while $k$ is the adsorption equilibrium constant which is temperature dependent according to the relation $[21,29,30]$.

The Langmuir and Temkin Isotherms were tested using the experimental data and the Langmuir isotherm gave the best fit. The equation of the Langmuir isotherm is:

$C / \theta=1 / k+C$ 
From a plot of $C / \theta$ against $C$, a straight line graph was obtained with a slope of 0.084 and an intercept of 0.113 on $C / \theta$ axis. The coefficient of correlation, $r^{2}$, gave the degree of fit between the experimental data and the isotherm equation. The value obtained was found to be 0.999 , which indicates a very good fit between the Langmuir isotherm and the experimental data.

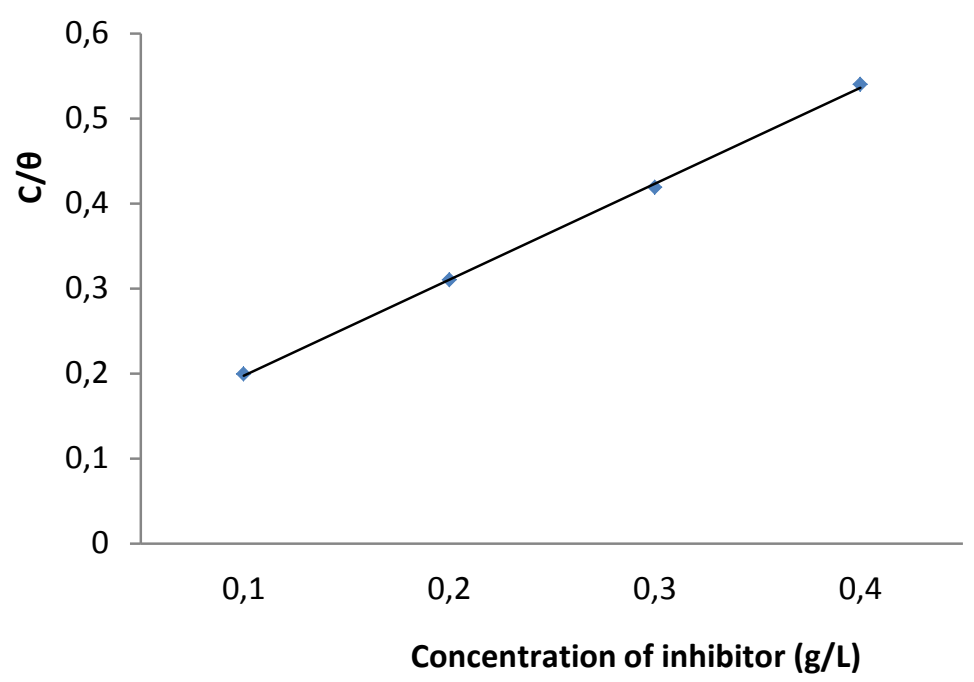

Figure 4: Langmuir adsorption isotherm for inhibition of aluminium in $0.25 \mathrm{M} \mathrm{KOH}$ by Palisota hirsute leaf extract

Using the value of intercept obtained from the graph and equations 5 a value of $-15.61 \mathrm{~kJ} \mathrm{~mol}^{-1}$ was obtained for $\Delta \mathrm{G}^{\mathrm{o}}$ ads. The very good fit of the experimental data with the Langmuir adsorption isotherm suggests that the Langmuir adsorption model is applicable in the corrosion inhibition mechanism. The negative value of $\mathrm{G}^{\mathrm{o}}{ }_{\mathrm{ads}}$, the Gibb's free energy of adsorption, obtained means that the adsorption process was spontaneous.

Table 1: Values of Langmuir isotherm parameters for aluminium 8011

\begin{tabular}{|c|c|c|c|c|}
\hline Plant extract & Intercept & Slope & $\mathbf{R}^{\mathbf{2}}$ & $\mathbf{G}_{\text {ads }}^{\mathbf{0}}\left(\mathbf{k J m o l} \mathbf{~}^{\mathbf{1}}\right)$ \\
\hline Palisota hirsute & 0.113 & 0.084 & 0.999 & -15.610 \\
\hline
\end{tabular}

It has been pointed out $[15,21,31]$ that generally, values of $\mathrm{G}_{\text {ads }}^{\mathrm{o}}$ up to $-20 \mathrm{kJmol}^{-1}$ are consistent with physical adsorption. The interactions involved in this mechanism are more or less weak electrostatic interactions between metal atoms and adsorbate species. In fact, the adsorption energies involved have the same range of energy values as the van der Waals bond energies. However, values of $\Delta \mathrm{G}^{\mathrm{o}}$ ads which are more negative than - $40 \mathrm{kJmol}^{-1}$ are associated with chemical adsorption, also called chemisorption. The mechanism involves charge sharing or charge transfer between the atoms of the metal and the adsorbate molecules. The associated bonds are strong and the corresponding bond energies could be as large as those characteristics of primary bonds in solids.

\section{CONCLUSION}

This study has shown that the presence of Palisota hirsute in $0.25 \mathrm{M} \mathrm{KOH}$ reduces the corrosion rate of aluminum 8011 in the environment. The efficiency of inhibition increases with an increase in the concentration of the inhibitor. The obtained experimental data fitted best into the Langmuir adsorption isotherm, signifying the formation of a single layer of inhibitor molecules onto aluminium alloy surface. The value of the Gibb's free energy of adsorption obtained suggests that the spontaneous physical adsorption of the plant extract molecules is the most likely inhibitory mechanism responsible for the reduction of the corrosion rate of the aluminium 8011 in $0.25 \mathrm{M}$ $\mathrm{KOH}$ containing Palisota hirsute leaf extract 


\section{REFERENCES}

[1] S. Caporali, A. Fossati, A. Lavacchi, I. Perissi, A. Tolstogouzov, U. Bardi, Aluminium electroplated from ionic liquids as protective coating against steel corrosion. Corros. Sci., 50 (2008) 534-539.

[2] H. Fang, K. Chen, Z. Zhang, C. Zhu, Effect of Yb addition on microstructure and properties of 7A60 aluminium alloy. Trans. Nonferrous Met. Soc. China. 18 (2008) 28-32.

[3] R. Rosaliza, W. B. Wan Nik, H. B. Senin, The effect of inhibitor on the corrosion of aluminium alloys in acidic solutions. Mater. Chem. Phys., 107 (2008) 281-288.

[4] E. E. Oguzie, G. N. Onuoha, E. N. Ejike, Effect of Gongronema latifolium extract on aluminium corrosion in acidic and alkaline media. Pigment Resin Technol., 36 (2007) 44-49.

[5] L. A. Nnanna, B. N. Onwuagba, I. M. Mejeha, K. B. Okeoma, Inhibition effects of some plant extracts on the acid corrosion of aluminium alloy. Afr. J. Pure Appl. Chem., 4 (2010) 11-16.

[6] L. A. Nnanna, W. O. John, O. Nwadiuko, Corrosion Inhibition Study of Aluminum AA3003 in Alkaline Medium by Palisota Hirsute Extract. International Journal of Engineering Research and Reviews 2 (2014) 113-118.

[7] W. D. Callister, G. R. David, Materials science and engineering: an introduction. Vol. 7. New York, Wiley, 2007.

[8] I. N. Obot, O. Egbedi, Adsorption characteristics and Corrosion Inhibitive properties of Clotrimazole for Aluminium Corrosion in Hydrochloric Acid. Int. J. Electrochem. Sci., 4 (2009) 1277-1288.

[9] H. Zhang, Y. Zuo, The improvement of corrosion resistance of Ce conversion films on aluminum alloy by phosphate post-treatment. Applied Surface Science 254.16 (2008) 49304935.

[10] E. E. Oguzie, Evaluation of some inhibitive effect of some plant extracts on the acid corrosion of mild steel. Corros. Sci. 50 (2008) 2993- 2998.

[11] E. E. Ebenso, Effect of methyl red and halide ions on the corrosion inhibition of aluminium in $\mathrm{H}_{2} \mathrm{SO}_{4}$ : Part 2. Bull. Electrochemica 20 (2004) 551-559.

[12] I. M. Mejeha, A. A. Uroh, K. B. Okeoma, G. A. Alozie, The inhibitive effect of Solanum melongena L. Leaf extract on the corrosion of aluminium in tetraoxosulphate (VI) acid. Afr. J. Pure Appl. Chem. 4 (2010) 158-165.

[13] E. E. Ebenso, N. O. Eddy, A. O. Odiongenyi, Corrosion inhibition and adsorption properties of methacarbanol on mild steel in acidic medium. Portugaliae Electrochemica Acta. 27 (2009) $13-22$.

[14] N.H. Helal, M. M. El-Rabiee, G. M. A. El-Hafez, W. A. Badawy, Environmentally safe corrosion inhibition of $\mathrm{Pb}$ in aqueous solutions, Journal of Alloys and Compounds 456 (2008) $372-378$.

[15] L. A. Nnanna, W. O. John, E. C. Emenike, U. Ihekoronye, I. I. Dike, Corrosion Inhibition Effect of Anthocleista Djalonensis on Mild Steel in 1.0 M HCL. Int'l Journal of Engineering Researches and Reviews 3 (2015) 31-36.

[16] T. Olabiyi, E. Oyedunmade, G. Ibikunle, O. Ojo, G. Adesina, K. Ogunniran, Chemical Composition and Bio-Nematicidal Potential of some Weed Extracts on Meloidogyne incognita under Laboratory Conditions. Medwell J. Plant Sci. 1 (2008) 30-35.

[17] A. Chetouani, B. Hammouti, T. Benhadda, M. Daoudi, Inhibitive action of bipyrazolic type organic compounds towards corrosion of pure iron in acidic media. Appl. Surf. Sci. (2005) 249-375. 
[18] S. A. Umoren, O. Ogbobe, E. E. Ebenso, U. J. Ekpe, Effect of halide ions on the corrosion inhibition of mild steel in acidic medium using polyvinyl alcohol. Pigment and Resin Technol. 35 (2006) $284-292$.

[19] S. Umoren, I. Obot, E. Ebenso, P. Okafor, Eco-friendly Inhibitors from Natural Occuring Exudate Gum for Aluminium Inhibition in Acidic Medium. Port. Electrochim. Acta. 26 (2008) 267-282.

[20] M. Bouklah, B. Hammouti, M. Lagrenee, F. Bentiss, Thermodynamic Properties of 2,5-bis(4methoxyphenyl)-1,3,4-oxadiazole as a Corrosion Inhibition for Mild Steel in Normal Sulphuric Acid Medium. Corros. Sci. 48 (2006) 28-31.

[21] L. A. Nnanna, I. U. Anozie, A. G. I. Avoaja, C. S. Akoma and E. P. Eti, Comparative study of corrosion inhibition of aluminium alloy of type AA3003 in acidic and alkaline media by Euphorbia hirta extract. African Journal of Pure and Applied Chemistry 5 (2011) 265-271.

[22] A. Popova, E. Sokolova, S. Raicheva, M. Christov, AC and DC study of the temperature effect on mild steel corrosion in acid mediain the presence of benzimidazole derivatives. Corrosion Sci. 45 (2003) 33-58.

[23] E. E. Oguzie, Corrosion inhibitive effect and adsorption behaviour of Hibiscus sabdariffa on mild steel in acidic media. Portugaliae Electrochemica Acta. 26 (2008) 303-314.

[24] E. E. Ebenso, U. J. Ekpe, S. Umoren, J. Ekerete, O. K. Abiola, N. C. Oforka, S. Martinez, Corrosion inhibition studies of some plant extracts on aluminium in acidic medium. J. Corros. Sci. Techol. 1 (2004) 96-101.

[25] S. B. Ulaeto, U. J. Ekpe, M. A. Chidiebere, E. E. Oguzie, Corrosion Inhibition of Mild Steel in Hydrochloric Acid by Acid Extracts of Eichhornia crassipes, International Journal of Materials and Chemistry 2 (2012) 158-164.

[26] P. O. Atanda, O. E. Olorunniwo, O. D. Alabi, O. O. Oluwole, Effect of Iso-Thermal Treatment on the Corrosion Behaviour of Low Carbon Steel (Nigerian C2R grade) in a Buffered Solution containing Chloride and Carbonate Ions, International Journal of Materials and Chemistry 2 (2012) 65-71.

[27] P. Okafor, M. Ikpi, I. Uwah, E. Ebenso, U. Ekpe, S. Umoren, Inhibitive action of Phyllanthus amarus on the corrosion of mild steel in acidic medium", Corrosion Science 50 (2008) 23102317.

[28] A. A. Inemesit, O. O. Nnanake-Abasi, Inhibition of Mild Steel Corrosion in Hydrochloric Acid Solution by Ciprofloxacin Drug, International Journal of Corrosion 2013 (2013).

[29] M. A. Ameer, E. Khamis, G. Al-Sanani, Adsorption studies of the effect of thiosemicarbazides on the corrosion of steel in phosphoric acid. Adsorpt. Sci. Tech. 18 (2000) 177-194.

[30] S. Martinez, Inhibitory mechanism of mimosa tannin using molecular modelling and substitutional adsorption isotherms. Mater. Chem. Phys. 77 (2002) 97-102.

[31] M. Iannuzzi, G. S. Frankel, Mechanisms of corrosion inhibition of AA2024-T3 by vanadates. Corros. Sci. 49 (2007) 2371-2391. 